\title{
A new high-temperature borehole fluid sampler: the Multi-Temperature Fluid Sampler
}

\author{
C. Geoffrey Wheat ${ }^{1}$, Christopher Kitts ${ }^{2}$, Camden Webb ${ }^{3}$, Rachel Stolzman ${ }^{2}$, Ann McGuire ${ }^{2}$, \\ Trevor Fournier $^{1}$, Thomas Pettigrew ${ }^{4}$, and Hans Jannasch ${ }^{5}$ \\ ${ }^{1}$ College of Ocean and Fisheries Sciences, University of Alaska Fairbanks, \\ P.O. Box 475, Moss Landing, CA 95039, USA \\ ${ }^{2}$ Robotic Systems Laboratory, Santa Clara University, Santa Clara, CA 95053, USA \\ ${ }^{3}$ Materials Engineering, California Polytechnic State University, San Luis Obispo, CA 93407, USA \\ ${ }^{4}$ Pettigrew Engineering, Milam, TX 75959, USA \\ ${ }^{5}$ Monterey Bay Aquarium Research Institute, Moss Landing, CA 95039, USA
}

Correspondence: C. Geoffrey Wheat (wheat@mbari.org)

Received: 5 February 2020 - Revised: 5 May 2020 - Accepted: 18 May 2020 - Published: 1 December 2020

\begin{abstract}
Deep ( $>1 \mathrm{~km}$ depth) scientific boreholes are unique assets that can be used to address a variety of microbiological, hydrologic, and biogeochemical hypotheses. Few of these deep boreholes exist in oceanic crust. One of them, Deep Sea Drilling Project Hole 504B, reaches $\sim 190^{\circ} \mathrm{C}$ at its base. We designed, fabricated, and laboratory-tested the Multi-Temperature Fluid Sampler (MTFS), a non-gas-tight, titanium syringe-style fluid sampler for borehole applications that is tolerant of such high temperatures. Each of the 12 MTFS units collects a single $1 \mathrm{~L}$ sample at a predetermined temperature, which is defined by the trigger design and a shape memory alloy (SMA). SMAs have the innate ability to be deformed and only return to their initial shapes when their activation temperatures are reached, thereby triggering a sampler at a predetermined temperature. Three SMAbased trigger mechanisms, which do not rely on electronics, were tested. Triggers were released at temperatures spanning from 80 to $181{ }^{\circ} \mathrm{C}$. The MTFS was set for deployment on International Ocean Discovery Program Expedition 385T, but hole conditions precluded its use. The sampler is ready for use in deep oceanic or continental scientific boreholes with minimal training for operational success.
\end{abstract}

\section{Introduction}

The current and future direction of scientific ocean drilling depends on technological advances to achieve a wide range of scientific objectives. Objectives related to microbial life in the subseafloor and a dynamic Earth represent two of the four current themes that guide scientific ocean drilling within the International Ocean Discovery Program (IODP; IODP Science Plan for 2013-2023). While advances in these areas have been achieved using traditional coring and sample analyses, nontraditional means of instrumenting boreholes and direct sampling of legacy boreholes continue to transform our knowledge of these themes (D'Hondt et al., 2019; Orcutt et al., 2011; Smith et al, 2011; Neria et al., 2016; Wheat et al., 2020). To meet new challenges afforded by future and legacy boreholes, including the potential for in situ manip- ulative experiments, a new arsenal of samplers and sensors needs to be developed.

Scientific ocean drilling during the past 5 decades has resulted in more than 100 cased boreholes, many of which are suitable for reentry and further discovery (Edwards et al., 2012). Such boreholes tap a range of thermal, hydrologic, physical, and crustal conditions, providing the underpinnings for a range of potential experiments to elucidate crustal and microbial evolution and function as well as the impact of both on ocean processes. Of special interest are the few deep boreholes that penetrate more than a kilometer below the seafloor, each taking many months to years to establish. As a result of natural geothermal heating from below, temperatures within such boreholes exceed $100^{\circ} \mathrm{C}$; Deep Sea Drilling Project (DSDP) Hole 504B reaches temperatures of 
more than $190^{\circ} \mathrm{C}$ at its base, which is $\sim 2000 \mathrm{~m}$ below the seafloor (Guerin et al., 1996). Additional warm, deep boreholes exist in continental settings (e.g., KTB; Emmermann and Lauterjung, 1997) and in active high-temperature hydrothermal systems (e.g., Brothers Arc Flux; de Ronde et al., 2019). To study in situ conditions within these challenging environments, a new array of sensors and samplers need to be developed. Standard electronics do not tolerate such temperatures and, in general, do not function above $150^{\circ} \mathrm{C}$ without costly vacuum jackets (dewars) or cooling mechanisms. Because of (a) the uniqueness of these warm, deep boreholes; (b) the aspiration to characterize the thermal limits of life within the crust; (c) the desire to elucidate waterrock reactions and crustal alteration in a natural setting; and (d) the lack of a fluid sampler that is inexpensive, easy to operate, and affords a versatile array of experimental possibilities, we developed the Multi-Temperature Fluid Sampler (MTFS). The MTFS is a non-gas-tight, syringe-style fluid sampler that employs no electronics. Instead, it incorporates a mechanical trigger that utilizes the thermal-response properties of a shape memory alloy (SMA), which is a precise mixture of metals that allows the alloy to be physically modified at room temperature and to return to its original shape at an activation temperature that depends on the composition of the alloy, the geometry of the SMA material, and the design of the trigger mechanism.

\section{Existing samplers}

Prior to the MTFS, borehole fluid samplers in the IODP inventory included the water-sampling temperature probe (WSTP), the Kuster sampler, and the single-phase fluid sample collection system from Schlumberger. The WSTP has been used for decades (Mottl and Gieskes, 1990) and is lowered on a wire to the desired depth with a preset timer that opens the intake valve. The pressure differential between in situ and surface $(\sim 100 \mathrm{kPa})$ pressure drives fluids into the sampler, possibly lysing microbial cells. Only $\sim 40 \mathrm{~mL}$ is collected in the sample tubing with $\sim 1 \mathrm{~L}$ spilling into a chamber that cannot be aseptically cleaned for trace metal and microbial determinations. The Kuster fluid sampler was most recently used on IODP Expedition 376 (Brothers Arc Flux; de Ronde et al., 2019). This sampler collects $\sim 500 \mathrm{~mL}$ of borehole fluid during a single lowering and is closed by a mechanical clock. However, the sample container is open during deployment, potentially exposing the sample container to contamination (e.g., accumulation of grease, microbial mats, and other particulates). Neither sampler can be preloaded with acid, microbial preservatives, or metabolic tracers, and only one sample can be collected during a single lowering.

More complex samplers require dedicated technicians, such as the single-phase fluid sample collection system from Schlumberger that was used in conjunction with the Quick- silver in situ fluid analyzer on IODP Expedition 337 (Inagaki et al., 2013). Multiple sample modules may be used. For example, six samples were collected on IODP Expedition 337 (Inagaki et al., 2013). Other complex samplers include the high-temperature two-phase downhole sampler from Thermochem Inc., which is a vacuum jacket-type, memory tool, and the positive displacement sampler and One Phase sampler from Leutert. The latter is a gas-tight system with an internal clock that opens and closes a valve. This system can collect a $0.6 \mathrm{~L}$ sample at temperatures to $180^{\circ} \mathrm{C}$ (Kampman et al., 2013).

\section{Design criteria}

The MTFS design was primarily based on the Walden-Weiss titanium sampler, which is a non-gas-tight fluid sampler that has been used for more than 4 decades to collect hydrothermal fluids at the seafloor (Von Damm et al., 1985), and the borehole fluid samplers mentioned above. To meet the physical requirements of IODP boreholes and ensure sample integrity, the design criteria included the capability of the sampler to be (a) cleaned for trace element analysis, (b) aseptic prior to deployment, (c) tolerant of temperatures greater than $250^{\circ} \mathrm{C}$, and (d) chemically inert. Additional criteria for flexibility in sample recovery and experimental design included the capability to be primed with a reagent, such as acid in order to keep metals mobilized; a stable isotope for in situ microbial rate studies; or a biocide. The sampler design also needed to consider the possibility of storing the sampler at in situ temperatures, either in the hole or on the ship, to conduct incubation and other time-dependent experiments. A large volume of sample $(1 \mathrm{~L})$ and an easy to access sampling port were desired to aliquot fluids into a range of sample containers for a myriad of chemical and microbial analytical assays. Additional design criteria included (a) a diameter that would allow the sampler to fit within the confines of the drill pipe used by IODP; (b) a modular framework so that multiple samplers with different treatments could be deployed during a single lowering; (c) compatibility with other borehole instruments; and (d) deployment with a wireline system, using either a drilling vessel, submersible, or remotely operated underwater vehicle. Most importantly, the sampler design had to include a temperature-sensitive trigger that was independent of electronics, could operate at temperatures from $\sim 80$ to $180^{\circ} \mathrm{C}$, and could withstand higher temperatures.

\section{Fabrication and testing}

To meet these design criteria we designed and fabricated a modular, $1 \mathrm{~L}$, syringe-style, non-gas-tight, titanium fluid sampler in which the sample is only in contact with titanium, two high-temperature silicone o-ring seals and a Viton fluoroelastomer gasket (Fig. 1). The syringe design affords sterile sample collection at in situ pressures, and the 


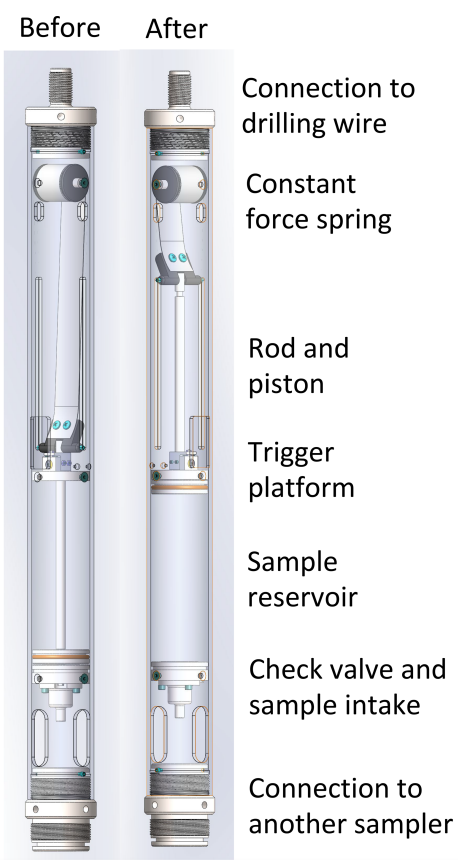

Figure 1. Cross section of a single module of the MTFS highlighting its primary components before the sampler is triggered and after.

sample is contained by a custom spring-loaded titanium and Viton gasket check valve. Because the sampler is not gastight, pressure within the sampler is the same as that outside the sampler, similar to the Walden-Weiss titanium fluid sampler. Thus, if dissolved gases in recovered fluids remain undersaturated at shipboard temperatures and pressures, either sampler (Walden-Weiss or MTFS systems) will provide reliable dissolved gas data. In contrast, if dissolved gases are supersaturated in either the Walden-Weiss or MTFS samplers, fluid and or gas will leak out of the sampler during recovery. In the case of the MTFS, fluids or gas would leak out of the Viton gasket check valve, again providing a sample at shipboard pressure.

A fluid sample is drawn slowly into the sample reservoir to prevent degassing, filling the reservoir within $\sim 10 \mathrm{~s}$. Upon recovery, a sample is withdrawn after detaching the constantforce spring from the piston (Fig. 1). Next, a titanium plug, which is adjacent to the intake and has a pipe thread, is removed. A titanium tube is then threaded into this opening with the other end of the tube attached to a sample container or collection device (e.g., syringe, filter, or bottles). Fluids are expelled by manually applying pressure to the piston, forcing fluid out of the sample chamber through the titanium tube and into the attached sampling apparatus.

Each sample unit is made of 35.5 -inch-long $(90.2 \mathrm{~cm}), 3-$ inch $(7.62 \mathrm{~cm})$ inner diameter (i.d.; schedule 40$)$ grade 2 titanium seamless tubing (Fig. 1) with ACME threads to connect units. Connectors were made from 3.75-inch $(9.525 \mathrm{~cm})$ titanium rod with ACME threads. The lower section of the unit
Table 1. Average temperature and standard deviation at which an SMA trigger was activated. Data from three trigger mechanisms and multiple discrete SMAs are listed for combinations that were tested more than three times.

\begin{tabular}{lr}
\hline Type of trigger & $\begin{array}{r}\text { Temperature and } \\
\text { standard deviation }\left({ }^{\circ} \mathrm{C}\right)\end{array}$ \\
\hline Spring & $80 \pm 1 ; 93 \pm 2$ \\
\hline Bolt & $102 \pm 2 ; 107 \pm 1 ; 126 \pm 3 ; 128 \pm 5 ;$ \\
& $136 \pm 3 ; 161 \pm 4 ; 174 \pm 3 ; 181 \pm 7$ \\
\hline Precision tube & $134 \pm 9 ; 152 \pm 5 ; 152 \pm 8 ; 155 \pm 7 ;$ \\
& $157 \pm 2 ; 159 \pm 4$ \\
\hline
\end{tabular}

provides a cavity for fluid mixing as the sampler descends within the borehole. Fluids from this cavity enter the sampler through a check valve and into the $1 \mathrm{~L}$ sample chamber as the piston extends to the base of the trigger platform. This platform acts as a guide for the piston and houses the trigger, which, when activated, releases a 28 -pound $(12.7 \mathrm{~kg})$ constant force spring to draw in the sample.

Two types of SMAs were used to trigger the samplers. The first was a commercially available Nitinol material (nickeltitanium SMA), available in spring form and suitable for triggers in the 80 to $90^{\circ} \mathrm{C}$ range. These springs are relatively weak; thus, they were used in a configuration that mechanically leverages the change in the SMA spring's form to release the constant force spring. Two springs were selected for use and tested at least five times by heating the MTFS module in a water-filled bath. The empirically determined activation temperatures were 80 and $93^{\circ} \mathrm{C}$, respectively, with a relative standard deviation of $<2 \%$ ("Spring" in Table 1).

A second type of SMA (CuAlNi) was produced in the shape of a $5 \mathrm{~mm}$ diameter rod by TiNi Aerospace. Portions of the rod were cut into 0.6-inch-long long $(1.52 \mathrm{~cm})$ pieces and machined to allow a notched titanium bolt to pass. TiNi Aerospace has a proprietary method in which an SMA is heated such that as it reverts back to its original shape, it breaks a notched titanium bolt. We tested this trigger process within the MTFS using a heated oil-filled (canola) bath to affect the SMA and release the tension on the constant force spring once the bolt broke (Fig. 2). Eight SMA pieces were tested, each at least three times, resulting in a range of release temperatures $\left(\sim 100-180^{\circ} \mathrm{C}\right)$ with a relative standard deviation of $<4 \%$ for each of the eight pieces ("Bolt" in Table 1).

Other SMAs pieces from this rod material were compressed within a new piece of precision stainless-steel tubing. A trigger was designed in which the SMA was ejected by a spring once the SMA was warmed to the prescribed temperature. Six SMA pieces from two alloys were tested, each at least three times, resulting in a range of release temperatures $\left(\sim 134\right.$ to $\left.159^{\circ} \mathrm{C}\right)$ with a relative standard deviation of $<7 \%$ for each of the six pieces ("Precision tube" in Table 1). Un- 


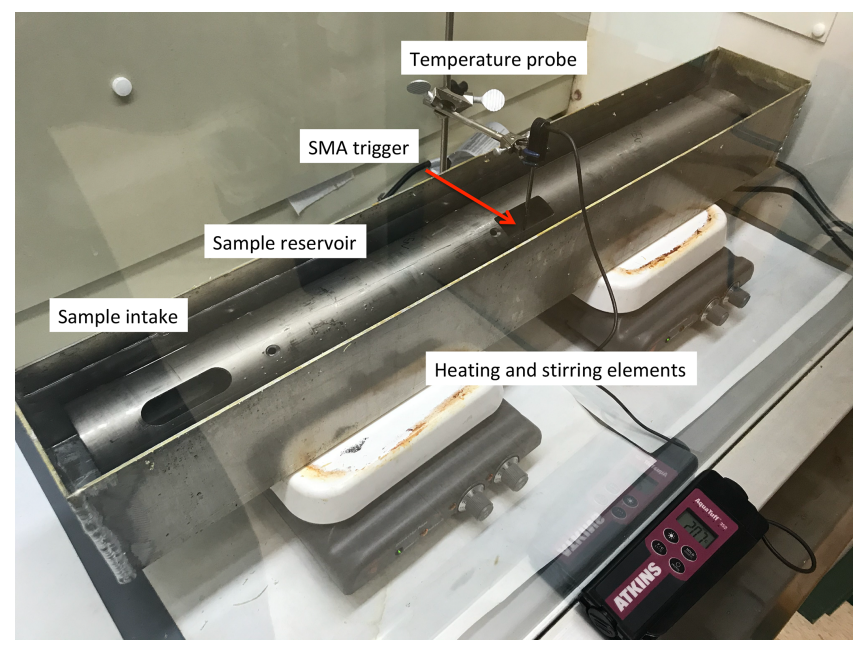

Figure 2. Tests of trigger mechanisms were conducted in a custom bath of canola oil within a chemical hood. The bath holds one 35.5-inch-long $(0.90 \mathrm{~m})$ MTFS module, two magnetic stir bars, and a temperature sensor. The temperature sensor is placed within millimeters of the shape metal alloy (SMA) to document the temperature at which the trigger is activated. Two heaters with magnetic stirrers keep the oil bath well mixed, heating the bath to $190^{\circ} \mathrm{C}$ in $1 \mathrm{~h}$.

like the other two triggers, this trigger was tested alone and not within the MTFS.

Similar to the Walden-Weiss samplers, the MTFS has no implodable volumes, and the bulk modulus of titanium requires pressures to deform the material that are well in excess of the deepest boreholes under hydrostatic pressure. The pressure effect on the activation temperature of these SMAs is about $5 \mathrm{~K} \mathrm{GPa}^{-1}$ (Kakeshita et al., 1988, 1999); thus, no pressure tests were conducted on the MTFS triggers. Except for a prototype, which was tested at the seafloor (31 MPa) to assess the piston-syringe and spring-style mechanism, all systems tests were conducted in water- or oil-filled baths, depending on the temperature of activation. We continue to improve the MTFS system. For example, in 2020 the "bolt" trigger option will be recalibrated using precision torque wrenches that will hopefully improve the repeatability and lower the standard deviation of the temperature that activates the trigger.

\section{Applications}

The first use of the MTFS was planned during the reentry of DSDP Hole 504B on IODP Expedition 385T "Panama Basin Crustal Architecture and Deep Biosphere: Revisiting Hole 504B and 896A" (Tominaga et al., 2019). The goal was to clear scientific equipment in both holes, sample borehole fluids, and log the boreholes. Neither hole was cleared; thus, the MTFS was not deployed (Fig. 3). DSDP Hole 504B is $\sim 190^{\circ} \mathrm{C}$ at the base of the open borehole (Guerin et al.,

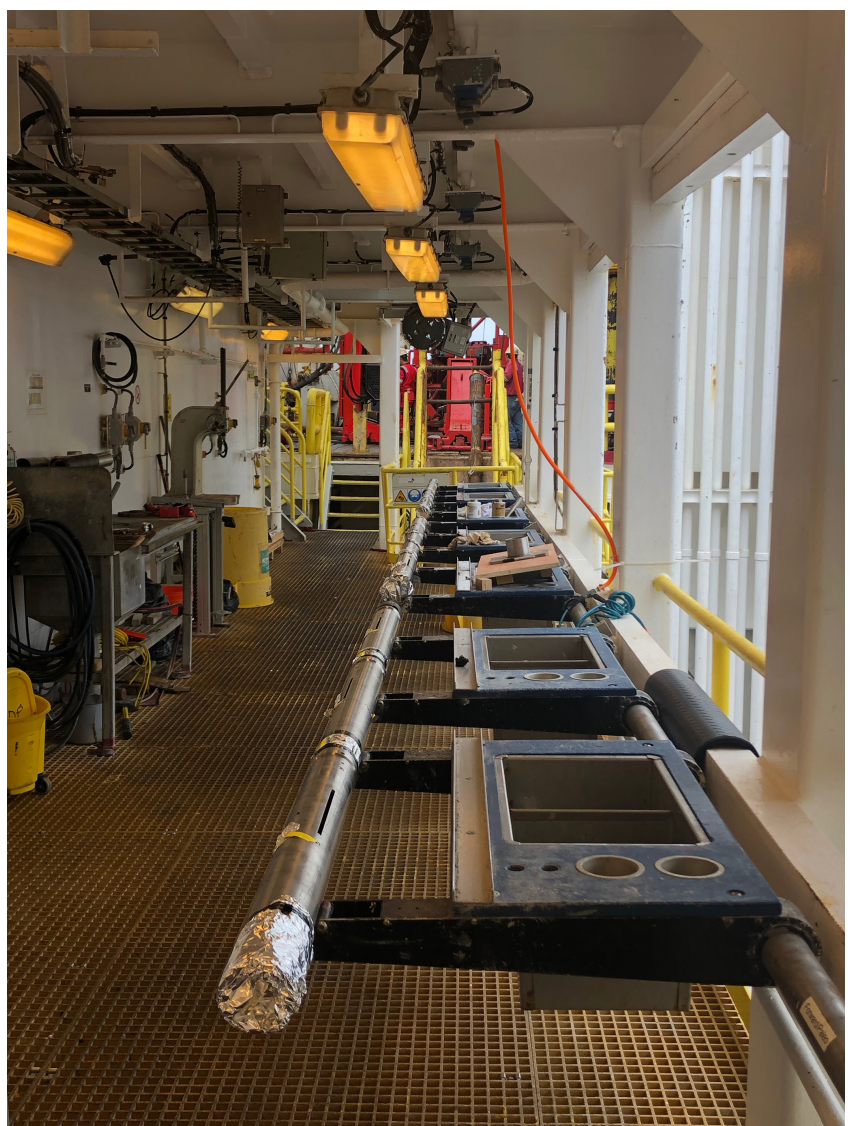

Figure 3. A total of 11 modules were combined in three section on the catwalk in anticipation for deployment within DSDP Hole 504B on IODP Expedition 385T in August 2019 (Tominaga et al., 2019). Final assembly and connection to other sensing instruments would occur on the rig floor, which is up the four steps at the end of the catwalk. Aseptic aluminum foil covers the fluid intake to minimize microbial contamination prior to deployment.

1996), making it an ideal hole to assess the thermal limits of life in basaltic crust. The current verified thermal limit for life is $122^{\circ} \mathrm{C}$ (Takai et al., 2008; Clarke, 2014); however, the thermal limit for life may reach or exceed $150{ }^{\circ} \mathrm{C}$ (Wharton, 2007; Hoehler, 2007), based on (1) protein and lipid structures that compensate for high temperatures, (2) the increased stability of ribosomal and transfer RNA at high temperatures, and (3) the increased thermal stability of proteins at higher pressures, among other arguments (Galtier and Lobry, 1997; Holland and Baross, 2003). The current MTFS design and availability of triggers allows for up to 12 samples to be collected during a single lowering in the interval from 80 to $181^{\circ} \mathrm{C}$.

A second deployment was proposed to collect flocculent material from Ocean Drilling Program (ODP) Hole 896A, which was based on a biofilm-forming microorganisms and images from a downhole camera (Becker et al., 2004; Nigro et al., 2012). This biofilm is distinctly different from those 
observed within the eastern flank of the Juan de Fuca Ridge, even though the thermal and chemical compositions of formation fluids are nearly identical. Differences may suggest site-specific characteristics or biogeographic influences. The MTFS triggers would allow for the collection of samples in the interval from 80 to $90^{\circ} \mathrm{C}$, which is the temperature at the base of the borehole.

For both deployments, we planned on attaching the elevated temperature borehole sensor (ETBS) tool, which measures borehole temperature and records measurements with electronics that are housed within a vacuum jacket (de Ronde et al., 2019). If a vacuum-jacketed system is not available, self-contained temperature recorders (i.e., Onset Hobo) can withstand temperatures to $\sim 150{ }^{\circ} \mathrm{C}$ before likely battery failure, but the data may be recoverable according to suppliers. We have not tested this possibility. Such data coupled with measurements of time and the amount of wire deployed would provide a measure of the depth within the borehole at which the samplers were triggered.

Although we were unable to deploy the MTFS during IODP Expedition 385T, the MTFS is suitable for use in a range of oceanic or continental boreholes where fluid collection is desired in the temperature range from 80 to $181^{\circ} \mathrm{C}$. As noted above, the syringe-style design of the MTFS allows for a broad range of priming fluids (e.g., acid, biocide, and metabolic tracers) to conduct a range of potential experiments. In addition, once recovered, the samplers can be placed in oil-filled baths for incubation experiments at in situ temperatures. Although not a current capability, the intake could be modified to filter a sample in situ. The simplicity of the sampler design affords other potential modifications to accommodate a range of community interests. The MTFS is available for community use. Readers interested in using the MTFS should contact the first author (wheat@mbari.org).

Data availability. Data are available in the text. Data from additional testing, specifications, and the operational manual will reside with IODP.

Author contributions. CGW and CK led this project. CW tested the bolt and tube triggers. RS and AM designed and tested the spring trigger. TF machined, modified, and troubleshot the MTFS. TP designed the system for use with IODP. HJ designed triggers and provided machine drawings. All authors contributed to the paper.

Competing interests. The authors declare that they have no conflict of interest.

Acknowledgements. We acknowledge the inspiration from David Johnson, an expert in SMA materials and properties. We thank John Van Hyfte, Bill Rhinehart, and Kevin Grigar for inspecting design elements for compatibility with the JOIDES Resolution.
We also thank Beth Orcutt and IODP technical staff for help with preparing and assembling the MTFS on IODP Expedition 385T. This is C-DEBI contribution 530.

Financial support. This research has been supported by the U.S. National Science Foundation (grant no. OCE-1830087; Ocean Technology and Interdisciplinary Coordination).

Review statement. This paper was edited by Thomas Wiersberg and reviewed by Jochem Kück and one anonymous referee.

\section{References}

Becker, K., Davis, E. E., Spiess, F. N., and Demoustier, C. P.: Temperature and video logs from the upper oceanic crust, Holes 504B and 896A, Costa Rica Rift flank: implications for the permeability of upper oceanic crust, Earth Planet. Sci. Lett., 222, 881-896, https://doi.org/10.1016/j.epsl.2004.03.033, 2004.

Clarke, A.: The thermal limits to life on Earth, Int. J. Astrobiol., 13, 141-154, https://doi.org/10.1017/S1473550413000438, 2014.

de Ronde, C. E. J., Humphris, S. E., Höfig, T. W., and the Expedition 376 Scientists: Brothers Arc Flux, Proc. IODP, 376, International Ocean Discovery Program, College Station, TX, USA, https://doi.org/10.14379/iodp.proc.376.2019, 2019.

D'Hondt, S., Inagaki, F., Orcutt, B. N., and Hinrichs, K. U.: IODP Advances in the understanding of subsurface seafloor life, Oceanography, 32, 198-207, https://doi.org/10.5670/oceanog.2019.146, 2019.

Edwards, K. J., Becker, K., and Colwell, F.: The deep, dark energy biosphere: intraterrestrial life on earth, Annu. Rev. Earth Planet. Sc., 40, 551-568, https://doi.org/10.1146/annurev-earth-042711105500, 2012.

Emmermann, R. and Lauterjung, J.: The German continental deep drilling program KTB: overview and major results, J. Geophys. Res.-Sol. Ea., 102, 18179-18201, https://doi.org/10.1029/96JB03945, 1997.

Galtier, N. and Lobry, J. R.: Relationships between genomic $\mathrm{G}+\mathrm{C}$ content, RNA secondary structures, and optimal growth temperature in prokaryotes, J. Mol. Evol., 44, 632-636, https://doi.org/10.1007/PL00006186, 1997.

Guerin, G., Becker, K., Gable, R., and Pezard, P. A.: Temperature mea-surements and heat-flow analysis in Hole 504B, in: Proc. IODP, Sci. Results, edited by: Alt, J. C., Kinoshita, H., Stokking, L. B., and Michael, P. J., 148, Ocean Drilling Program, College Station, TX, USA, 291-296, https://doi.org/10.2973/odp.proc.sr.148.141.1996, 1996.

Hoehler, T. M.: An energy balance concept for habitability, Astrobiology, 7, 824-838, https://doi.org/10.1089/ast.2006.0095, 2007.

Holland, M. E. and Baross, J. A.: Limits to Life in Hydrothermal Systems, in: Energy and mass transfer in marine hydrothermal systems, edited by: Halbach, P., Tunnicliffe, V., and Hein, J. R., Dahlem University Press, Berlin, Germany, 235-248, 2003.

Inagaki, F., Hinrichs, K.-U., Kubo, Y., and the Expedition 337 Scientists: Proc. IODP, Integrated Ocean Drilling Program Management International, 337, Tokyo, Japan, Inc., https://doi.org/10.2204/iodp.proc.337.2013, 2013. 
Kakeshita, T., Yoshimura, Y., Shimizu, K. I., Endo, S., Akahama, Y., and Fujita, F. E.: Effect of hydrostatic pressure on martensitic transformations in $\mathrm{Cu}-\mathrm{Al}-\mathrm{Ni}$ shape memory alloys, Trans. JPN I Met., 29, 781-789, https://doi.org/10.2320/matertrans1960.29.781, 1988.

Kakeshita, T., Saburi, T., Kind, K., and Endo, S.: Martensitic transformations in some ferrous and non-ferrous alloys under magnetic field and hydrostatic pressure, Phase Transit., 70, 65-113, https://doi.org/10.1080/01411599908240678, 1999.

Kampman, N., Maskell, A., Bickle, M. J., Evans, J. P., Schaller, M., Purser, G., Zhou, Z., Gattacceca, J., Peitre, E. S., Rochelle, C. A., Ballentine, C. J., Busch, A., and Scientists of the GRDP: Scientific drilling and downhole fluid sampling of a natural $\mathrm{CO}_{2}$ reservoir, Green River, Utah, Sci. Dril., 16, 33-43, https://doi.org/10.5194/sd-16-33-2013, 2013.

Mottl, M. J. and Gieskes, J. M.: Chemistry of waters sampled from oceanic basement boreholes, 1979-1988, J. Geophys. Res.-Sol. Ea., 95, 9327-9342, https://doi.org/10.1029/JB095iB06p09327, 1990.

Neira, N. M., Clark, J. F., Fisher, A. T., Wheat, C. G., Haymon, R. M., and Becker, K.: Cross-hole tracer experiment reveals rapid fluid flow and low effective porosity in the upper oceanic crust, Earth Planet. Sc. Lett., 450, 355-365, https://doi.org/10.1016/j.epsl.2016.06.048, 2016.

Nigro, L. M., Harris, K., Orcutt, B. N., Hyde, A., Clayton-Luce, S., Becker, K., and Teske, A.: Microbial communities at the borehole observatories on the Costa Rica Rift flank (Ocean Drilling Program Hole 896A), Front. Microbiol., 3, article 232, https://doi.org/10.3389/fmicb.2012.00232, 2012.

Orcutt, B. N., Bach, W., Becker, K., Fisher, A. T., Hentscher, M., Toner, B. M., Wheat, C. G., and Edwards, K. J.: Colonization of subsurface microbial observatories deployed in young ocean crust, ISME J., 5, p. 692, https://doi.org/10.1038/ismej.2010.157, 2011.
Smith, A., Popa, R., Fisk, M., Nielsen, M., Wheat, C. G., Jannasch, H. W., Fisher, A. T., Becker, K., Sievert, S. M., and Flores, G.: In situ enrichment of ocean crust microbes on igneous minerals and glasses using an osmotic flowthrough device, Geochem., Geophy., Geosy., 12, Q06007, https://doi.org/10.1029/2010GC003424, 2011.

Takai, K., Nakamura, K., Toki, T., Tsunogai, U., Miyazaki, M., Miyazaki, J., Hirayama, H., Nakagawa, S., Nunoura, T., and Horikoshi, K.: Cell proliferation at $122 \mathrm{C}$ and isotopically heavy $\mathrm{CH}_{4}$ production by a hyperthermophilic methanogen under highpressure cultivation, P. Natl. Acad. Sci. USA, 105, 10949-10954, https://doi.org/10.1073/pnas.0712334105, 2008.

Tominaga, M., Orcutt, B. N., Blum, P., and the Expedition 385T Scientists: Expedition 385T Preliminary Report: Panama Basin Crustal Architecture and Deep Biosphere, International Ocean Discovery Program, https://doi.org/10.14379/iodp.pr.385T.2019, 2019.

Von Damm, K. L., Edmond, J. M., Grant, B., Measures, C. I., Walden, B., and Weiss, R. F.: Chemistry of submarine hydrothermal solutions at $21^{\circ} \mathrm{N}$, East Pacific Rise, Geochim. Cosmochim. Ac., 49, 2197-2220, https://doi.org/10.1016/00167037(85)90222-4, 1985.

Wharton, D. A.: Life at the limits: organisms in extreme environments, Cambridge University Press, Cambridge, UK, 2007.

Wheat, C. G., Becker, K., Villinger, H., Orcutt, B. N., Fournier, T., Hartwell, A., and Paul, C.: Subseafloor cross-hole tracer experiment reveals hydrologic properties, heterogeneities, and reactions in slow spreading oceanic crust, Geochem., Geophy., Geosy., 21, e2019GC008804, https://doi.org/10.1029/2019GC008804, 2020. 